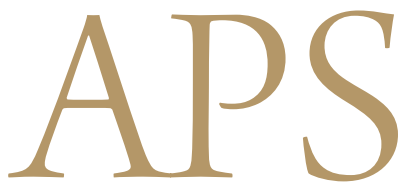

Archives of Plastic Surgery

\title{
A Retrospective Review of Iatrogenic Skin and Soft Tissue Injuries
}

\author{
Tae Geun Lee ${ }^{1}$, Seum Chung ${ }^{2}$, Yoon Kyu Chung ${ }^{1}$ \\ ${ }^{1}$ Department of Plastic and Reconstructive Surgery, Yonsei University Wonju College of Medicine, Wonju; \\ ${ }^{2}$ Department of Plastic and Reconstructive Surgery, Ilsan Hospital, National Health Insurance Corporation, Goyang, Korea
}

Background Even though the quality of medical and surgical care has improved remarkably over time, iatrogenic injuries that require surgical treatment including injuries caused by cast and elastic bandage pressure, extravasation, and dopamine-induced ischemia still frequently occur. The goal of this study was to estimate the incidence and analyze the distribution of iatrogenic injuries referred to our department.

Methods A retrospective clinical review was performed from April 2006 to November 2010. In total, 196 patients (116 females and 80 males) were referred to the plastic surgery department for the treatment of iatrogenic injuries. We analyzed the types and anatomic locations of iatrogenic complications, along with therapeutic results.

Results An extravasation injury (65 cases, 37.4\%) was the most common iatrogenic complication in our study sample, followed by splint-induced skin ulceration, dopamineinduced necrosis, prefabricated pneumatic walking brace-related wounds and elastic bandage-induced wounds. Among these, prefabricated pneumatic walking brace-related complication incidence increased the most during the 5-year study period.

Conclusions The awareness of the very common iatrogenic complications and its causes may allow physicians to reduce their occurrence and allow for earlier detection and referral to a plastic surgeon. We believe this is the first study to analyze iatrogenic complications referred to a plastic surgery department in a hospital unit.

Keywords Extravasation of diagnostic and therapeutic materials / Medical errors / Pressure sore
Correspondence: Yoon Kyu Chung Department of Plastic and Reconstructive Surgery, Wonju Christian Hospital, Yonsei University Wonju College of Medicine, 20 Ilsan-ro, Wonju 220-701, Korea Tel: +82-33-741-0611 Fax: +82-33-741-4202 E-mail: ykchung@yonsei.ac.kr

Received: 21 Dec 2011 - Revised: 11 May 2012 • Accepted: 14 May 2012

pISSN: 2234-6163 • elSSN: 2234-6171 • http://dx.doi.org/10.5999/aps.2012.39.4.412 • Arch Plast Surg 2012;39:412-416

\section{INTRODUCTION}

A troubling aspect of medical care, wherever it is delivered is its capacity to cause unintended injury, disabilities, and disease. Even though the quality of medical and surgical care has remarkably improved, various types of iatrogenic injuries, including cast and elastic bandage pressure wounds, extravasation, and dopamine-induced necrosis, frequently occur. Using a large consecutive series of patients, we examined the rates and types of iatrogenic complications, along with the possible associated factors, requiring plastic surgery.

\section{METHODS}

This is a retrospective study of patients admitted to our hospital. A clinical chart review of cases from April 2006 to November 2010 revealed that 196 patients ( 116 females and 80 males) had been referred to the Department of Plastic Surgery for iatrogenic

Copyright $\odot 2012$ The Korean Society of Plastic and Reconstructive Surgeons

This is an Open Access article distributed under the terms of the Creative Commons Attribution Non-Commercial License (http://creativecommons.org/

licenses/by-nc/3.0/) which permits unrestricted non-commercial use, distribution, and reproduction in any medium, provided the original work is properly cited.

www.e-aps.org 
injuries. These injuries were caused by extravasation, dopamineinduced necrosis, splint sores, prefabricated pneumatic walking braces, or elastic bandages, among others. Patients ranged in age from premature infants and newborns to 82 years of age. The mean age of the sample group was 49 years.

Bedridden patients with pressure sores on the hip area were excluded from the study because the following factors increase the likelihood of developing pressure sores: immobility, malnutrition, incontinence, hypoalbuminemia, spinal cord injury, stroke, hypertension, reduced consciousness, and fractures.

\section{Case 1}

A 57-year-old woman was admitted to the Department of Orthopedics of our institution due to a left tibiofibular fracture. Calcium gluconate extravasation at an intravenous access site (the dorsal radial side of the wrist) occurred and was treated using intravenous cannula removal and compressive dressings. Ten days after treatment, the patient was admitted to the plastic surgery unit for skin necrosis at the extravasation site. Debridement of the nonviable tissue resulted in tendon exposure. A reverse radial forearm island fasciocutaneous flap was used to cover the wound. Satisfactory aesthetic and functional results

\section{Fig. 1. Skin and soft tissue necrosis by extravasation injury}

(A) Skin and soft tissue necrosis caused by calcium gluconate extravasation. (B) At 6 months after flap surgery. The defect was covered using a reverse radial forearm island fasciocutaneous flap.
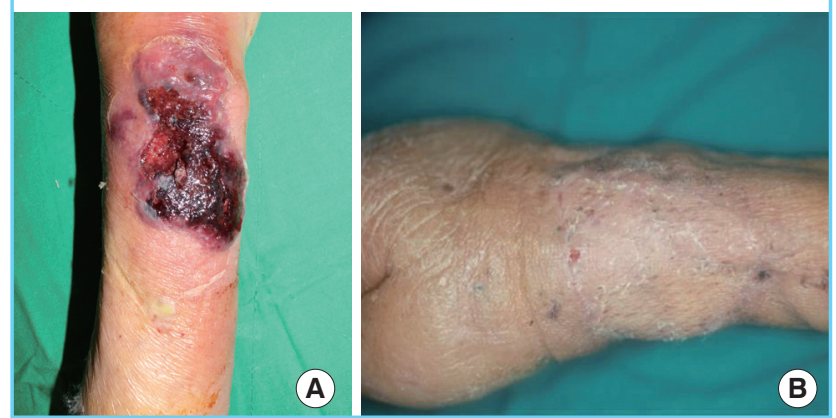

were obtained (Fig. 1).

\section{Case 2}

A 3-month-old male infant was transferred to our department from a local pediatric clinic because of a skin injury caused by an elastic bandage. Two days prior to referral, the patient had suffered an abrasion on the left middle finger that was treated simply with an ointment dressing and an elastic bandage at the local clinic. The next day, the pediatrician found that the skin color had changed to dark red secondary to congestion. Due to his age, the patient was unable to communicate whether there was tightness, pain, or discomfort after the elastic bandaging was applied. Immediately after he was transferred to our hospital, we applied local wound oxygen therapy. We maintained local oxygen therapy for 1 week and we achieved satisfactory results (Fig. 2).

\section{RESULTS}

The most common type of iatrogenic injury in our study was extravasation secondary to medication (58 patients, 33.4\%), and the most common extravasation injury site was the dorsum of the hand. In descending order, the other common sites for extravasation included the forearm, cubital fossa, upper arm, and dorsum of the foot. Metabolic and chemotherapeutic drugs were the most common agents causing medication extravasation injuries. Of the 58 patients who could be followed up after consulting the plastic surgery department, 40 had wounds that healed without skin grafts or flaps, while the remaining 18 patients required surgery for extensive skin necrotic injuries (12 of these patients required skin grafts, and 6 patients required flaps) (Table 1). As a result, $31 \%$ of the extravasation injuries required surgery.

Splint-induced ulcers were the second most common iatrogenic complication (49 patients, $28.2 \%$ ). This type of injury had been detected later than any other complication after onset; advanced ulcers were frequently observed at the time of con-

\section{Fig. 2. Elastic bandage induced ulcer}

(A) Elastic bandage induced ulcer. Three-month-old infant with an ulcer on the left 3rd finger. (B) Ten days after local oxygen therapy. (C) Two months after the elastic bandage induced injury.
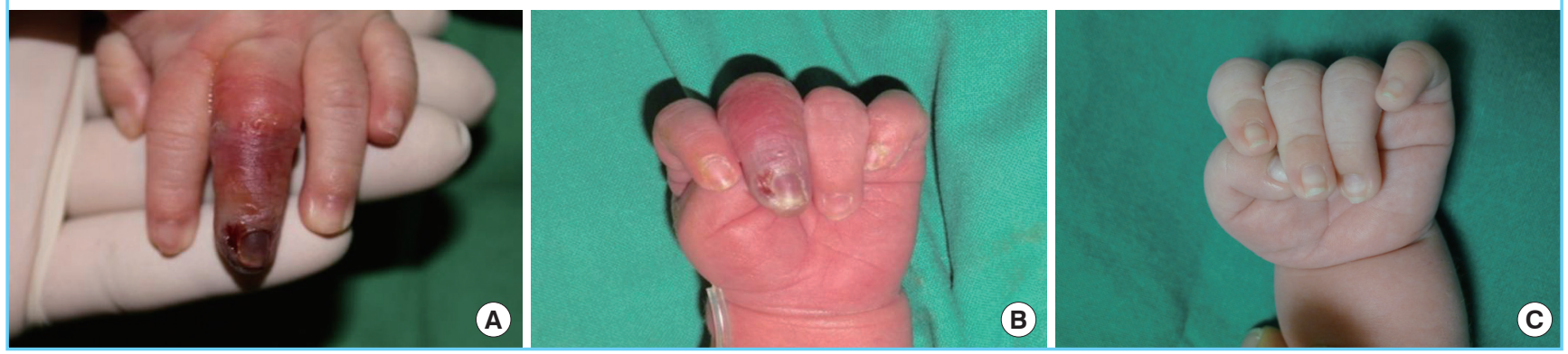
sultation (Fig. 3). Of the 49 patients with splint-induced ulcers, 18 healed without surgery after minor skin necrosis. A total of 17 patients required skin grafts, and 11 required flap surgery such as a reverse sural island flap or lateral malleolar perforator flap. Three patients were treated with primary wound closure (Table 1). Vasopressor (dopamine)-induced necrosis of the extremities was the third most common iatrogenic injury (16 patients, 9.2\%) (Table 1, Fig. 4). Fig. 3 presents a patient who developed cardiogenic shock due to acute myocardial infarction and required hospitalization in an intensive care unit (ICU). Noradrenaline $(1.3 \mu \mathrm{g} / \mathrm{kg} / \mathrm{min})$ was administered together with $10 \mu \mathrm{g} / \mathrm{kg} / \mathrm{min}$ of dobutamine. Within 2 days, the patient began

\section{Fig. 3. Splint induced ulcer}

(A) Splint-induced ulcer of the heel. (B) Lateral malleolar perforator flap was used to cover the defect. (C) Six months after flap surgery.
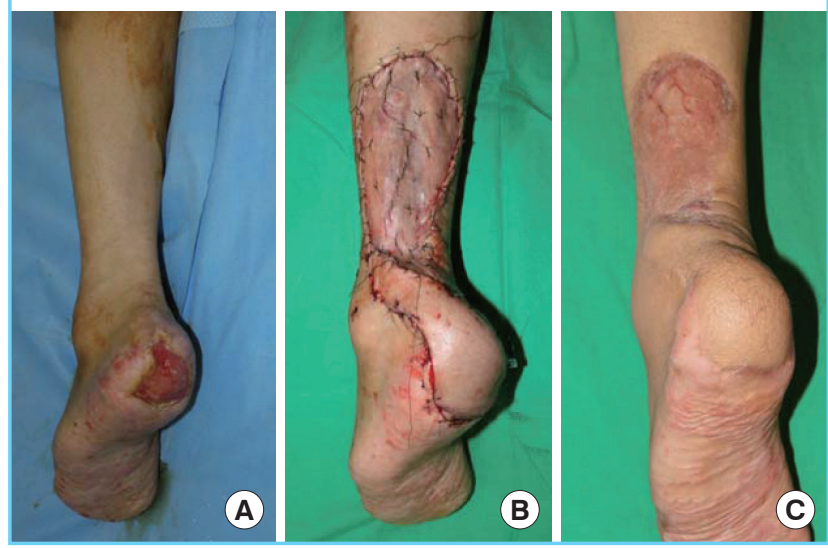

to exhibit livedo reticularis, cyanosis, vesicles, and bullae (some were hemorrhagic bullae) on the chest, abdomen, and upper and lower extremities with a negative Nikolsky sign. On ICU day 3 , gangrene of the distal fingers and toes were observed (Fig. 4). Amputations of the vasopressor-induced necrosis sites were required in 13 patients. This is the most serious iatrogenic complication due to its amputation rate (Table 1).

Skin ulceration induced by a prefabricated walking brace was the fourth most common injury (15 patients, $8.6 \%$ ). The most commonly affected areas included the medial and lateral malleoli (8 patients), followed by the dorsa of the foot and knee. Of the prefabricated walking brace cases, $46.6 \%$ needed surgery (Table 1). Eleven patients had skin injury induced by elastic bandages. All of the wounds had healed after conservative management. Local oxygen therapy was used in 6 cases that had an elastic bandage applied within the 12 hours prior to oxygen therapy treatment and for whom the injured area's skin color

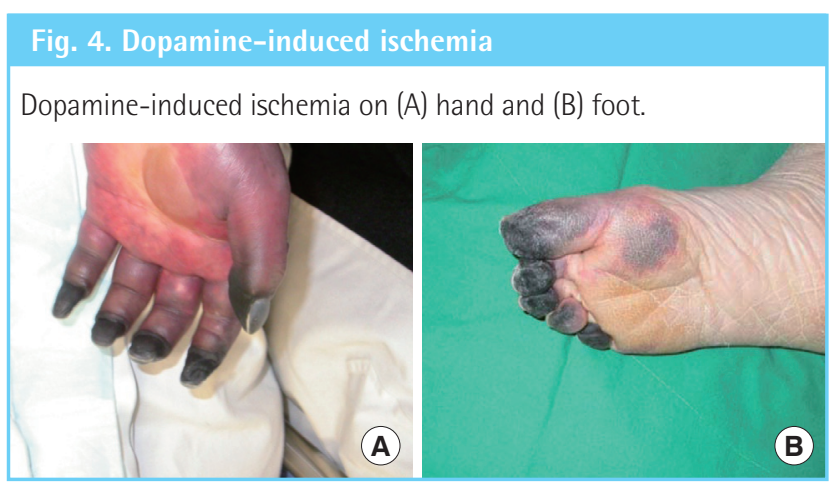

Table 1. Main iatrogenic injury results

\begin{tabular}{|c|c|c|c|}
\hline Type of injury & $\begin{array}{c}\text { Rate of } \\
\text { surgical procedure (\%) }\end{array}$ & Result & Number and ratio $(\%)$ \\
\hline Extravasation $(n=58)$ & 31 & $\begin{array}{l}\text { Minor skin necrosis/delayed healing } \\
\text { Skin graft } \\
\text { Regional flap (adipofascial flap, etc.) } \\
\text { Free flap (radial forearm, etc.) }\end{array}$ & $\begin{array}{l}40 \\
12(20.7) \\
4(6.9) \\
2(3.4)\end{array}$ \\
\hline Splint-induced ulcer $(n=49)$ & 63.3 & $\begin{array}{l}\text { Minor skin necrosis/delayed healing } \\
\text { Primary repair } \\
\text { Skin graft } \\
\text { Regional flap (reverse sural flap, etc) } \\
\text { Free flap (anterolateral thigh, } \\
\text { latissimus dorsi, etc.) }\end{array}$ & $\begin{aligned} 18 \\
3(6.1) \\
17(34.7) \\
7(14.3) \\
4(8.2)\end{aligned}$ \\
\hline Vasopressor-induced necrosis $(n=16)$ & 81.2 & $\begin{array}{l}\text { Minor skin necrosis/delayed healing } \\
\text { Skin graft } \\
\text { Ragional flap } \\
\text { Free flap } \\
\text { Amputation }\end{array}$ & $\begin{array}{l}3 \\
0 \\
0 \\
0 \\
13(81.2)\end{array}$ \\
\hline Prefabricated walking brace skin injury $(n=15)$ & 46.6 & $\begin{array}{l}\text { Minor skin necrosis/delayed healing } \\
\text { Skin graft } \\
\text { Ragional flap (supra malleolar, etc.) }\end{array}$ & $\begin{array}{l}8 \\
5(33.3) \\
2(13.3)\end{array}$ \\
\hline Elastic-bandage-induced skin injury $(n=11)$ & 27.2 & $\begin{array}{l}\text { Minor skin necrosis/delayed healing } \\
\text { Local hyperbaric oxygen therapy } \\
\text { Skin graft } \\
\text { Amputation }\end{array}$ & $\begin{array}{l}2 \\
6(54.5) \\
2(18.2) \\
1(9)\end{array}$ \\
\hline
\end{tabular}


had changed to dark red with congestion. We supplied pure oxygen to the wound area using a portable inflatable device for 24 hours a day. We maintained local wound oxygen therapy for 1 week at 750 to $760 \mathrm{~mm} \mathrm{Hg}$ of pressure. All the patients healed without complication. Other iatrogenic complications reviewed included povidone-iodine related burns and a neonatal injury during delivery.

\section{DISCUSSION}

Iatrogenic injuries or wounds are complications that occur as a result of medical treatment by physicians or other member of the health care team. The causes and severity of iatrogenic injuries vary, but in severe wound cases, consulting a plastic surgeon for wound treatment may be warranted. The iatrogenic injuries that are commonly referred to plastic surgeons for treatment include extravasation injuries, splint-induced ulcers, and injuries secondary to elastic bandages. Until now there has been no systematic long-term analytic study of iatrogenic complications, even within departments other than plastic surgery. We examined the actual incidence of iatrogenic injury at our hospital and systemically analyzed the treatment results after referral.

The analysis of the proportional changes during the study period showed a decrease in the absolute number of referred cases over time. The most prevalent iatrogenic injuries observed in this study were extravasation injuries and splint ulcers. However, with the increasing range of rehabilitation therapy, a significant increase in iatrogenic injuries caused by prefabricated walking braces was noted (Fig. 5).

An extravasation injury during intravenous infusion therapy was the most common iatrogenic complication. Various treatment for extravasation injury have been described [1]. If injuries are superficial and detected immediately, they can improve with prompt interventions and phentolamine injections. If the wounds are deep, and in cases of late diagnosis, conservative wound management has been recommended [2]. This includes

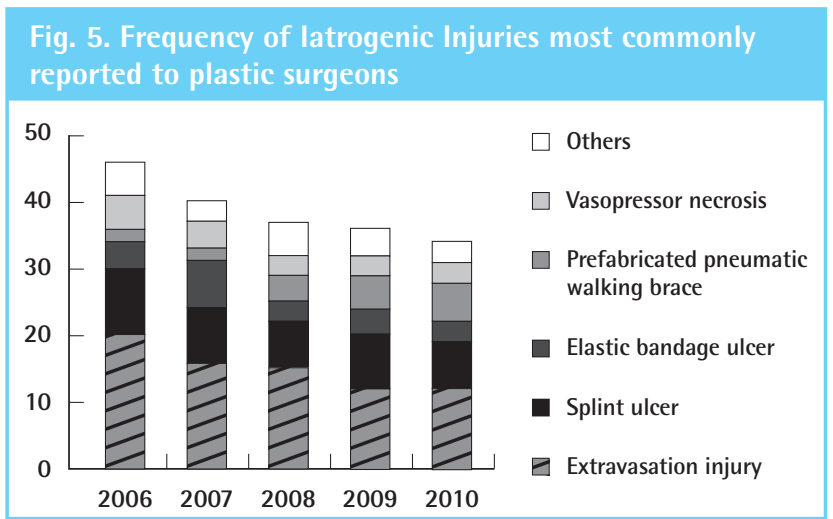

wound care until tissue necrosis was established, debridement of necrotic tissue, secondary wound healing, and intensive physical therapy. Reconstruction is normally delayed until the residual deformity has been established and scar maturation has occurred $[3,4]$. The pathophysiology of skin necrosis caused by extravasation is not well understood. Hyperosmotic edema and local electrolyte imbalance with subsequent ischemia are considered to be the major factors inducing tissue damage. A skin graft provides good wound coverage when sufficient viable dermal and subcutaneous tissue is available in the wound bed.

Most cast and splint-related iatrogenic injuries were ulcerations induced by pressure. Iatrogenic skin ulceration is the most common complication defined by prior researchers, and it is often caused by focal pressure from a wrinkled, unpadded, or underpadded area over a bony prominence or underlying soft tissue $[5,6]$. Ensuring that the padding is adequate, smooth, and without indentations, during application, can minimize the incidence. If detected early, cast- and splint-induced wounds almost always respond positively to simple wound-healing treatments. Ischemic necrosis leading to the loss of digits or limbs can occur as in the case of tissue infiltration with dopamine (Fig. 4).

Dopamine is widely used as a medication due to its cardiac inotropic effects. The treatment for vasopressor ischemia (dopamine, dobutamine, etc.) is inadequately understood. Prior research has reported that the alpha-adrenergic vasoconstriction effects of dopamine play a primary role in soft tissue necrosis. Therefore, alpha-adrenergic antagonists have been used for the treatment of ischemia [7]. Embolic complications and hypovolemia are associated risk factors for tissue necrosis. Peripheral vasoconstriction from dopamine may lead to thrombotic complications of disseminated intravascular coagulation and, thus, lead to tissue ischemic changes [8,9]. Based on our study, vasopressor-induced necrosis appears to be a critical iatrogenic injury that can lead to amputation. We also believe that delayed referral contributes to this outcome. Cases of soft tissue ischemia induced by vasopressors are usually referred to a plastic surgeon several days after the first onset of acrocyanosis. In many cases, dopamine administration continues and no treatment is initiated early despite progressive tissue ischemia. Early recognition of acrocyanosis by physicians is paramount for achieving the best prognosis.

When an elastic bandage is applied to a wound, it is difficult to determine the amount of pressure being applied by the bandage. Excessive pressure will commonly cause ischemia and soft tissue necrosis. In cases of a skin injury induced by an elastic bandage, most patients experience pain and excessive pressure; therefore, earlier detection is achieved compared to other cases of iatrogenic complications. However, babies, especially neona- 
tal infants, cannot directly confirm their experience of tightness or pain after an elastic bandage has been applied. We were presented with 5 cases of pressure injuries secondary to tight and circumferential bandage wrapping in neonates. We provided local wound oxygen therapy for 3 infants, resulting in satisfactory healing (Fig. 2). Through this study we also noted several risk factors for chemical burn injury in the operation room. Tourniquet pressure above underlying cotton padding that has been exposed to moisture or liquids can lead to skin-softening and tissue disintegration [10]. The macerated skin becomes more permeable to povidone-iodine and prone to damage from friction and irritation. Sterilizing skin with alcohol can further decrease the skin's resistance to chemical burn injury. The operation time also plays an important role in causing iatrogenic injuries. Most cases with complications had procedures lasting more than 2 hours. Long-term skin maceration, tourniquet pressure, and friction, along with irritating chemicals and alcohol are believed to cause skin damage.

One of the major limitations of this study is the small sample size, which was due to the fact that patients from only one medical center were included. A more systematic review is needed in order to propose future treatment modalities for iatrogenic complications that have been referred to plastic surgeons. Early identification of iatrogenic complications will assist plastic surgeons in developing more effective intervention protocols to improve patient care outcomes.

\section{REFERENCES}

1. Salameh Y, Shoufani A. Full-thickness skin necrosis after arginine extravasation: a case report and review of literature. J Pediatr Surg 2004;39:e9-11.

2. Gault DT. Extravasation injuries. Br J Plast Surg 1993;46: 91-6.

3. Loth TS, Eversmann WW Jr. Extravasation injuries in the upper extremity. Clin Orthop Relat Res 1991;(272):248-54.

4. Casanova D, Bardot J, Magalon G. Emergency treatment of accidental infusion leakage in the newborn: report of 14 cases. Br J Plast Surg 2001;54:396-9.

5. Guyton GP. An analysis of iatrogenic complications from the total contact cast. Foot Ankle Int 2005;26:903-7.

6. Ceelen KK, Stekelenburg A, Loerakker S, et al. Compression-induced damage and internal tissue strains are related.J Biomech 2008;41:3399-404.

7. Boltax RS, Dineen JP, Scarpa FJ. Gangrene resulting from infiltrated dopamine solution. N Engl J Med 1977;296:823.

8. Buchanan N, Cane RD, Miller M. Symmetrical gangrene of the extremities associated with the use of dopamine subsequent to ergometrine administration. Intensive Care Med 1977;3:55-6.

9. Hoff JV, Peatty PA, Wade JL. Dermal necrosis from dobutamine. N Engl J Med 1979;300:1280.

10. Nahlieli O, Baruchin AM, Levi D, et al. Povidone-iodine related burns. Burns 2001;27:185-8. 